\title{
Scalable Production of Cobalt Phthalocyanine Nanotubes: Efficient and Robust Hollow Electrocatalyst for Ammonia Synthesis at Room Temperature
}

Uttam Kumar Ghorai ${ }^{1}$, Sourav Paul ${ }^{1}$, Biswajit Ghorai ${ }^{1}$, Ashadul Adalder ${ }^{1}$, Samadhan Kapse ${ }^{2}$, Ranjit Thapa ${ }^{2}$, Abharana Nagendra ${ }^{3}$ and Amal Gain ${ }^{1}$

${ }^{1}$ Department of Industrial Chemistry \& Applied Chemistry, Swami Vivekananda Research Centre, Ramakrishna Mission Vidyamandira, Belur Math, Howrah - 711202, India

${ }^{2}$ Department of Physics, SRM University - AP, Amaravati 522240, Andhra Pradesh, India

${ }^{3}$ Atomic \& Molecular Physics Division, Bhabha Atomic Research Centre, Mumbai - 400085, India

Corresponding author:

*Email: uttam.indchem@vidyamandira.ac.in, uttamindchem00@gmail.com

\section{Contents}

SI 1. Determination of ammonia $\left(\mathrm{NH}_{3}\right)$

SI 2. Determination of hydrazine $\left(\mathrm{N}_{2} \mathrm{H}_{4}\right)$

SI 3. Determination of $\mathrm{NO}_{\mathrm{x}}$ contaminants

SI 4. Isotope labelling experiment and quantification by NMR method

SI 5. Quantitative estimation of ammonia and determination of faradaic efficiency

SI 6. Density Functional Theory (DFT) calculations

SI 7. XANES and EXAFS experiments

SI 8. FTIR spectrum of CoPc nanotubes (NTs) \& Table S1

SI 9. Pictorial representation of H-type cell 
SI 10. UV-vis absorption spectra and calibration curve for determination of $\mathrm{NH}_{4}{ }^{+}$

SI 11. UV-vis absorption spectra and calibration curve for determination of $\mathrm{N}_{2} \mathrm{H}_{4}$

SI 12. NMR spectra and calibration curve for determination of $\mathrm{NH}_{4}{ }^{+}$

SI 13. Comparative bar diagram(s) of average $\mathrm{NH}_{3}$ yield rate by UV-vis and NMR method

SI 14. UV-vis absorption spectra and calibration curve for determination of $\mathrm{NO}_{\mathrm{x}}$

SI 15. UV-vis absorption spectra for the formation of $\mathrm{N}_{2} \mathrm{H}_{4}$

SI 16. UV-vis absorption spectra to show $\mathrm{NO}_{x}$ does not exist in the ${ }^{14} \mathrm{~N}_{2}$ gas (99.999\% purity)

SI 17. UV-vis absorption of CoPc NTs sample at $-0.3 \mathrm{~V} v s$ RHE for different cycles

SI 18. XRD and TEM images of CoPc NTs after durability test

SI 19. XANES spectra at the Co K-edge of CoPc NTs before and after electrolysis along with $\mathrm{CoO}$ and Co foil, Table S2 and Co K-edge EXAFS fitting result for $\mathrm{k}^{2}$ space.

SI 20. DFT study of the free-energy diagrams of $\mathrm{N}_{2}$ adsorption on possible active sites

SI 21. Table S3: Comparison of the NRR activity for CoPc NTs with other transition metal based electrocatalyst in aqueous solution under ambient conditions

SI 22. References

\section{SI 1: Determination of ammonia $\left(\mathrm{NH}_{3}\right)$}

The concentration of ammonia produced via electrochemical NRR (ENRR) was detected using UV-visible spectroscopic means using the indophenol blue method. Methodically, $2 \mathrm{ml}$ of coloring solution (1 M sodium hydroxide* solution containing $5 \mathrm{wt} \%$ trisodium citrate dihydrate* and $5 \mathrm{wt} \%$ salicylic acid* (Merck Co., Ltd.)*), $1 \mathrm{ml}$ of oxidizing solution (0.05 M sodium hypochlorite solution (4\% w/v available chlorine) (Merck Co., Ltd.)) and $0.2 \mathrm{ml}$ of 
catalyst solution (1.01g (3.34 mmol) sodium nitroprusside dihydrate (Loba Chemie Co., Ltd)) were added to $2 \mathrm{ml}$ solution taken from the electrolytic cell after NRR.

The solution was incubated at room temperature for two hours, and then analyzed spectrophotometrically. The absorption spectrum showed maximum absorbance at $655 \mathrm{~nm}$, hitherto indicating the formation of indophenol. The calibration was done using standard ammonium chloride (Merck Co., Ltd.) solution (of varying concentration, $\{0.0,0.2,0.4,0.6,0.8$, $1.0(\mu \mathrm{g} / \mathrm{mL})\})$ with the fixed concentration of $\mathrm{HCl}$ as used in the ENRR experiments, the plot of concentration and absorbance were measured. From the Figure S4, the fitting curve $(y=0.225 x$ $\left.+0.012 ; \mathrm{R}^{2}=0.999\right)$ revealed an optimized linear correlation between absorbance and concentration of ammonia, after three repeated calibrations.

\section{SI 2: Determination of Hydrazine $\left(\mathrm{N}_{2} \mathrm{H}_{4}\right)$}

The hydrazine generated via ENRR was determined quantitatively spectrophotometrically using Watt and Chrisp method. ${ }^{1}$ In detail, the colored solution was prepared by $5.99 \mathrm{~g}$ of para(dimethylamino) benzaldehyde (Merck Co. Ltd.) was added to $30 \mathrm{ml} \mathrm{HCl}$ (concentrated) (Merck Co. Ltd.) and $300 \mathrm{ml}$ of absolute ethanol (Merck Co. Ltd.). Then $5 \mathrm{ml}$ of the electrolyte after ENRR experiment was taken and added with $5 \mathrm{ml}$ of colored solution, and then after stirring for 10 minutes, kept at the standing condition for further 5 minutes in a dark room at room temperature, then the absorbance spectrum of the solution was measured using UV-vis spectrophotometer, the maximum absorbance was quantified at $455 \mathrm{~nm}$. The calibration plot was made in the following way: at first, a series of varying concentrations of hydrazine-monohydrate as standard solutions $(0.0,0.2,0.4,0.6,0.8,1.0,1.2 \mu \mathrm{g} / \mathrm{mL})$ were made in $0.1 \mathrm{M} \mathrm{HCl}$. Then the volume was adjusted to $5 \mathrm{ml}$ using $0.1 \mathrm{M} \mathrm{HCl}$. Then $5 \mathrm{ml}$ of as prepared hydrazine-hydrate 
solution were added to $5 \mathrm{ml}$ of color solution and stirred at room temperature for $10 \mathrm{mins}$, then after stirring, the solution was kept in dark at room temperature for 10 mins; then UV-visible spectroscopy was done and the maximum absorbance was measured at $455 \mathrm{~nm}$. The plot of concentration and absorbance curves (Figure S6) yielded a fitting plot $\left(\mathrm{y}=1.441 \mathrm{x}+0.079 ; \mathrm{R}^{2}=\right.$ 0.999) that showed a virtuous linear relationship between the concentration of hydrazinemonohydrate and absorbance, after three independent calibrations were done then it was reported for estimation of hydrazine.

\section{SI 3: Determination of $\mathrm{NO}_{\mathrm{x}}$ Contaminants}

The quantitative determination of $\mathrm{NO}_{\mathrm{x}}$ was carried out using a spectrophotometric technique using $N$-(-1-naphthyl)-ethylenediamine dihydrochloride. ${ }^{2}$ The tinting solution was prepared by dissolution of $0.5 \mathrm{~g}$ of sulfanilic acid* in $90 \mathrm{ml}$ of millipore water and $5 \mathrm{ml}$ acetic acid* (Merck)* followed by the addition of $5 \mathrm{mg}$ of $\mathrm{N}$-(1-naphthyl)-ethylenediamine dihydrochloride $^{\$}$ (Loba Chemie) $)^{\$}$ and then making the solution to $100 \mathrm{ml}$. Then, $1 \mathrm{ml}$ of electrolyte was added to 4 $\mathrm{ml}$ of coloring solution. Then the solution was incubated for 15 minutes, and then an ultravioletvisible spectrophotometer was utilized to obtain the absorption spectrum. The calibration plots (concentration-absorbance curves) were made using sodium nitrite* (Merck)* solution with a series of concentrations in $0.1 \mathrm{M} \mathrm{HCl}$ (solvent). The plot of absorption versus concentration (Figure S13), generates a fitting plot $\left(\mathrm{y}=0.0953 \mathrm{x}-0.0012 ; \mathrm{R}^{2}=0.999\right)$, it showed a linear relationship of absorbance and concentration of $\mathrm{NO}_{\mathrm{x}}$. We conclude from (Figure S15), the UVvis absorption spectra of $0.1 \mathrm{M} \mathrm{HCl}$ background and ${ }^{14} \mathrm{~N}_{2}$ ultra-high purity grade $(99.999 \%$ purity) purged in electrolyte, that $\mathrm{NO}_{\mathrm{x}}$ was not present in the feeding gas. Hence it is confirmed that ammonia is formed by reduction of feeding ${ }^{14} \mathrm{~N}_{2}$ gas. 


\section{SI 4: Isotope labelling experiments and quantification by ${ }^{1} \mathrm{H}$ NMR method}

The isotope labelling experiment utilized ${ }^{15} \mathrm{~N}_{2}\left(98\right.$ atom $\%{ }^{15} \mathrm{~N}$ Sigma-Aldrich Co.) as the purged gas to throw light upon the origin of ammonia formation. After ${ }^{15} \mathrm{~N}_{2}$ gas was purged then ENRR was conducted at $-0.3 \mathrm{~V}$ (vs RHE) for 2 hours, the formed ${ }^{15} \mathrm{NH}_{4}{ }^{+}$was determined by ${ }^{1} \mathrm{H}$ nuclear magnetic resonance (Bruker $400 \mathrm{MHz}$, USA) with $\mathrm{d}^{6}$ DMSO (Cambridge Isotope Laboratories Inc.) The NMR analyte was prepared by concentrating $20 \mathrm{ml}$ electrolyte to $\sim 2 \mathrm{ml}$, then $0.25 \mathrm{ml}$ of concentrated solution was taken and added to $0.25 \mathrm{ml} \mathrm{d} \mathrm{d}^{6} \mathrm{DMSO}$, and then the NMR test was carried out. Similarly, the quantitative determination of ${ }^{14} \mathrm{NH}_{4}{ }^{+}$was done using ${ }^{14} \mathrm{~N}_{2}(99.999 \%$ ultra-high grade purity) as the feed gas. For calibration purpose ${ }^{14}\left(\mathrm{NH}_{4}\right)_{2} \mathrm{SO}_{4}$ was used as benchmark. ${ }^{2}$ To further validate the quantitative formation of ${ }^{15} \mathrm{NH}_{4}{ }^{+}$, calibration samples were prepared using ${ }^{15} \mathrm{NH}_{4} \mathrm{Cl}$ (98 atom\% ${ }^{15} \mathrm{~N}$ Sigma-Aldrich Co.) and the experiment was carried by purging ${ }^{15} \mathrm{~N}_{2}$ (98 atom\% ${ }^{15} \mathrm{~N}$ Sigma-Aldrich Co.) gas.

\section{SI 5: Quantitative estimation of ammonia}

The rate of formation of ammonia was calculated in the following way:

$$
\text { Rate of } \mathrm{NH}_{3}=\frac{\mathrm{C}_{\mathrm{NH}_{3}} \times \mathrm{V}}{\mathrm{t} \times \mathrm{m}}
$$

Where ' $\mathrm{C}_{\mathrm{NH}_{3}}$ ' is concentration of ammonia generated, ' $\mathrm{V}$ ' is volume of the electrolyte, ' $\mathrm{t}$ ' is electrochemical reduction reaction time and ' $\mathrm{m}$ ' is mass of the catalyst loaded to the working electrode.

The Faradaic efficiency for ENRR, denoted as ratio of the total charge required to produce ammonia via electrolysis to the total charge passed through the electrode during electrolysis 


$$
\mathrm{FE}=\frac{\left(3 \times \mathrm{F} \times \mathrm{C}_{\mathrm{NH}_{3}} \times \mathrm{V}\right)}{\mathrm{M} \times \mathrm{Q}}
$$

Where ' $\mathrm{F}$ ' is the Faraday Constant, ' $\mathrm{C}_{\mathrm{NH}_{3}}$ ' is concentration of ammonia produced; ' $\mathrm{V}$ ' is volume of the electrolyte, ' $\mathrm{M}$ ' is the molecular mass of ammonia, ' $\mathrm{Q}$ ' is the total charge passed through the electrode during ENRR experiment.

\section{SI 6: Density Functional Theory (DFT) calculations}

The First-principles calculations were performed by using density functional theory (DFT) implemented in the Vienna $A b$ initio Simulation Package (VASP). ${ }^{3}$ Perdew Burke-Ernzerhof (PBE) of the Generalized Gradient Approximation (GGA) for the exchange-correlation effect and projector-augmented wave (PAW) pseudopotential were employed. ${ }^{4}$ The cutoff energy for plane-wave basis set to $450 \mathrm{eV}$. The convergence threshold for the energy and force was set to 1 $\times 10^{-6} \mathrm{eV}$ and $0.01 \mathrm{eV} / \AA$, respectively. The Brillouin zone sampled at the gamma $\mathrm{K}$ point. The interaction between repeating images is avoided by using a vacuum in all directions (15 $\AA$ ).

The free energy profile is used to estimate the theoretical overpotential that defines the performance of a catalyst for the nitrogen reduction reaction (NRR). The Gibbs free energies $(G)$ are calculated by using the following equation, $\mathrm{G}=\mathrm{E}+\mathrm{ZPE}-\mathrm{TS}-\mathrm{neU}$, where $\mathrm{E}$ is the DFT energy, ZPE is the zero-point energy, TS is the entropic term, $\mathrm{n}$ is the number of electrons transferred and $\mathrm{U}$ is the applied potential at the electrode. ${ }^{5}$ Here, we have considered that the TS and ZPE of adsorbed atoms/ions are negligible to that of the gaseous phase at room temperature and ambient pressure. Here, the values of entropies and zero-point energies for the free molecules are considered from the chemical database (https://janaf.nist.gov.). 


\section{SI 7: XANES and EXAFS Experiments}

XANES and EXAFS experiments on Cobalt Pthalocyanine NTs post and pre electrolysis samples were investigated at the Energy Scanning EXAFS beamline (BL-09) at Indus-2 Synchrotron source $(2.5 \mathrm{GeV}, 300 \mathrm{~mA})$ at the Raja Ramanna Centre for Advanced Technology (RRCAT), Indore, India, ${ }^{6-7}$ where beam line operates in the photon energy domain of 4-25 KeV. The beamline optics composed of $\mathrm{Rh} / \mathrm{Pt}$ coated collimating meridional cylindrical mirror operates to collimate the beam. This mirror is used preceding DCM for higher harmonic rejection to specified extent. The collimated beam undergoes monochromatization by a Si (111) $(2 \mathrm{~d}=6.2709 \AA)$ based on double crystal monochromator (DCM). Second crystal of DCM is a sagittal cylindrical crystal, which is utilized for horizontal focusing of beam while other $\mathrm{Rh} / \mathrm{Pt}$ coated bendable post mirror faced downwards is applied for vertical focusing of beam at sample position.

During samples testing, the data has been recorded at Ni K-edges in fluorescence mode. For present sample, the measurement is done in fluorescence mode using a Si drift detector (Vortex detector) at 45deg geometry. Rejection of higher harmonic content in the X-ray beam is guided by detuning second crystal of DCM. The coefficient of absorption $\mu$ is found by the relation:

$$
I_{T}=I_{0} e^{-\mu x}
$$

where, ${ }^{x}$ denotes thickness of absorber and spectrum was acquired as an energy function of scanning the monochromator over specified range. The rejection of the higher harmonics content in X-ray was carried out by detuning of second crystal of DCM using the piezo motor to a level such that flux of beam at the outlet of DCM is reduced to less than $30 \%$ of the flux at its inlet. 
To take heed of oscillations in absorption spectra $\mu(E)$ has been converted to the absorption function $\chi(E)$ mentioned as follows: ${ }^{8}$

$$
\chi(E)=\frac{\mu(E)-\mu_{0}(E)}{\Delta \mu_{0}\left(E_{0}\right)}
$$

where, $E_{0}$ is the absorption edge energy, $\mu_{0}\left(E_{0}\right)$ is the bare atom background and $\Delta \mu_{0}\left(E_{0}\right)$ is the step in $\mu(E)$ value at the absorption edge. The energy dependent absorption coefficient $\chi(E)$ has been changed to wave number dependent absorption coefficient $\chi(k)$ using the following relation,

$$
K=\sqrt{\frac{2 m\left(E-E_{0}\right)}{\hbar^{2}}}
$$

where, $\mathrm{m}$ is the electron mass. $\chi(k)$ is weighted by $k^{2}$ to amplify the oscillation at high $k$ and the $\chi(k) k^{2}$ functions are fourier transformed in $R$ space to generate $\chi(R)$ versus $\mathrm{R}$ plots as far as real distances from the center of an absorbing atom. A cluster of EXAFS data analysis tool available with Demeter software package have been used to perform EXAFS data analysis. ${ }^{9}$ The process includes background reduction as well as Fourier transform to obtain the $\chi(R)$ versus $\mathrm{R}$ plots from absorption spectra (ATHENA software), generation of theoretical EXAFS spectra beginning from the supposed crystallographic structure (utilizing ATOMS subroutine) and finally fitting of experimental data in conjugation with theoretical spectra using ARTEMIS software. 


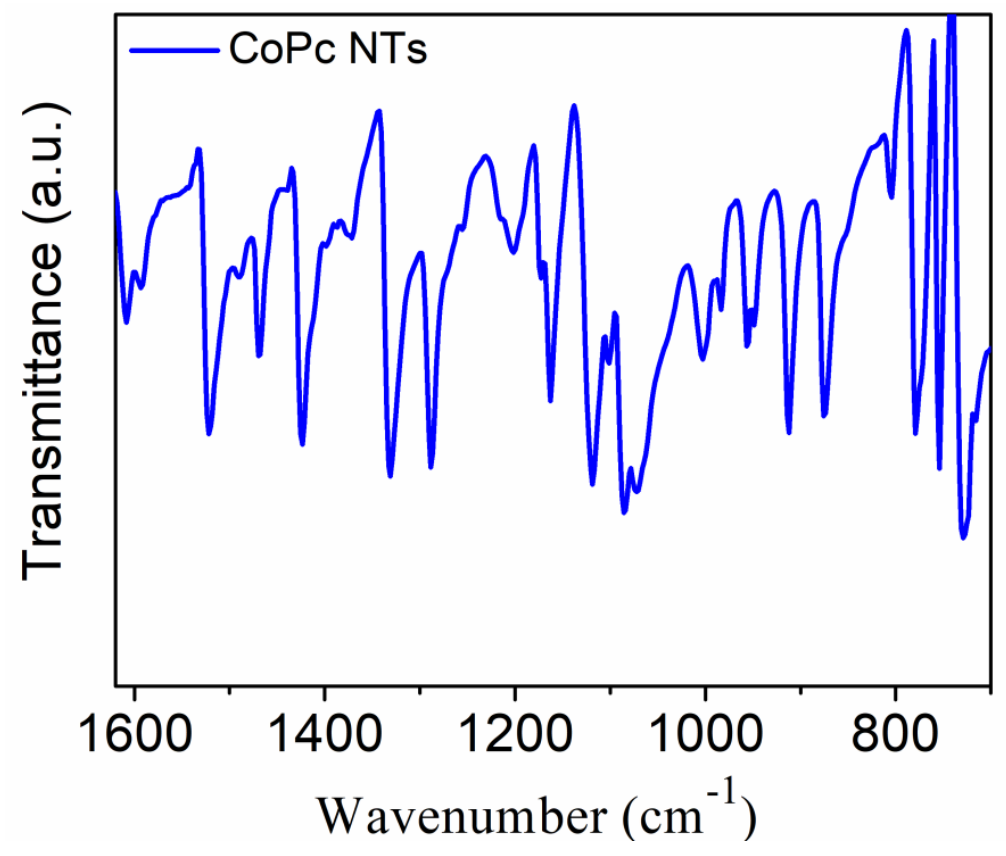

Figure S1: FTIR spectrum of CoPc NTs

Table 1: FTIR bonding characteristics of CoPc NTs ${ }^{10,11}$

\begin{tabular}{|l|l|}
\hline Wavenumber $\left(\mathrm{cm}^{-1}\right)$ & Assignment \\
\hline $754 \mathrm{~cm}^{-1}$ & Co-N bond vibration \\
\hline $780 \mathrm{~cm}^{-1}$ & C=N in plane stretching vibration \\
\hline $1086 \mathrm{~cm}^{-1}$ & C-H in plane deformation \\
\hline $1073 \mathrm{~cm}^{-1}$ & $v(\mathrm{C}-\mathrm{N})$ in plane \\
\hline $1469 \mathrm{~cm}^{-1}$ & C-C stretching in isoindole \\
\hline $1119 \mathrm{~cm}^{-1}$ & isoindole totally symm. \\
\hline $1163 \mathrm{~cm}^{-1}$ & $\delta_{\mathrm{C}-\mathrm{H} \text { (in plane }+ \text { isoindole })}$ \\
\hline $1522 \mathrm{~cm}^{-1}$ & C=N stretching \\
\hline $1331 \mathrm{~cm}^{-1}$ & C-C stretching in isoindole \\
\hline $1289 \mathrm{~cm}^{-1}$ & C-H in plane deformation $\left(\delta_{\mathrm{C}-\mathrm{H}}\right)$ \\
\hline
\end{tabular}




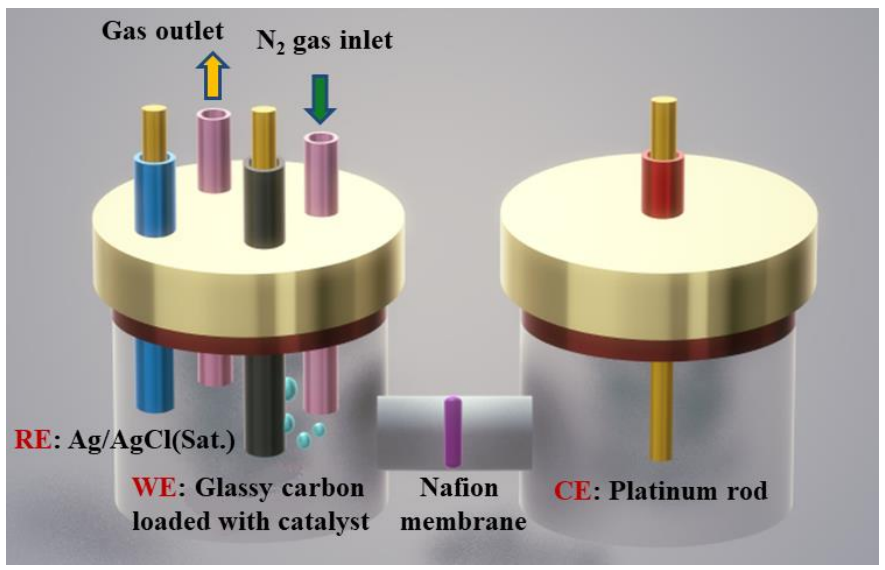

Figure S2: Pictorial representation of H-type cell

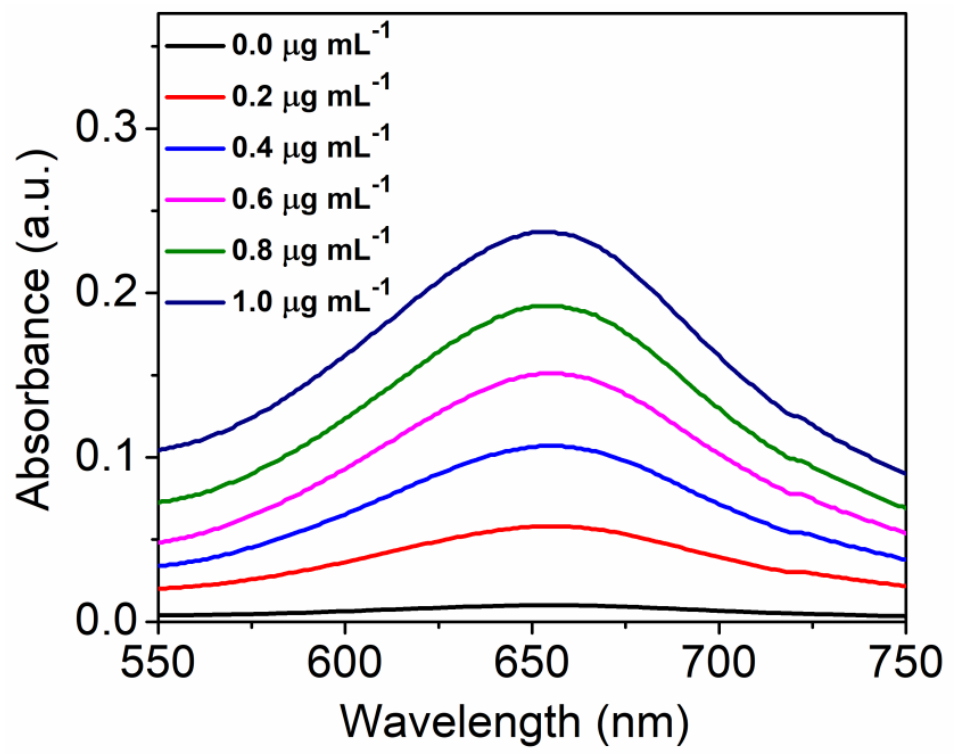

Figure S3: UV-vis spectra of the given conc. of Ammonium Chloride solution stained with indophenol indicator after $7200 \mathrm{sec}$ incubation period. 


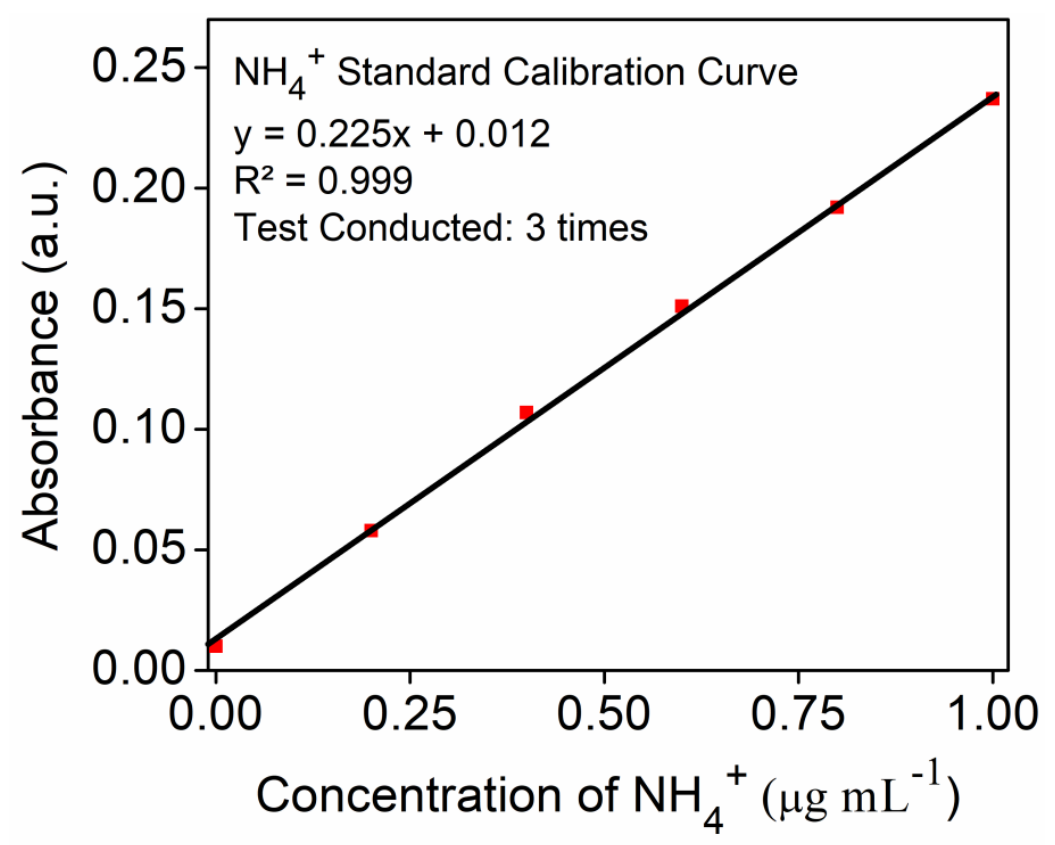

Figure S4: Calibration curve used for the determination of $\mathrm{NH}_{4}^{+}$concentration

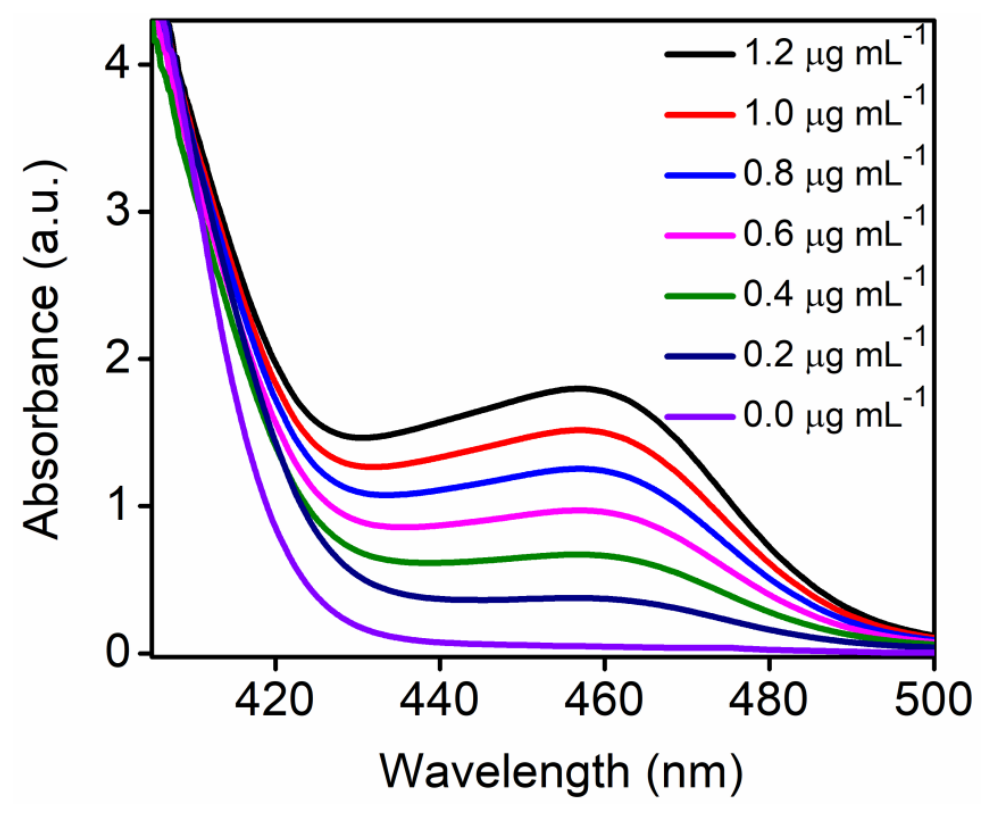

Figure S5: UV-vis absorption spectra of different $\mathrm{N}_{2} \mathrm{H}_{4}$ concentration after incubated for $600 \mathrm{sec}$ under ambient conditions. 


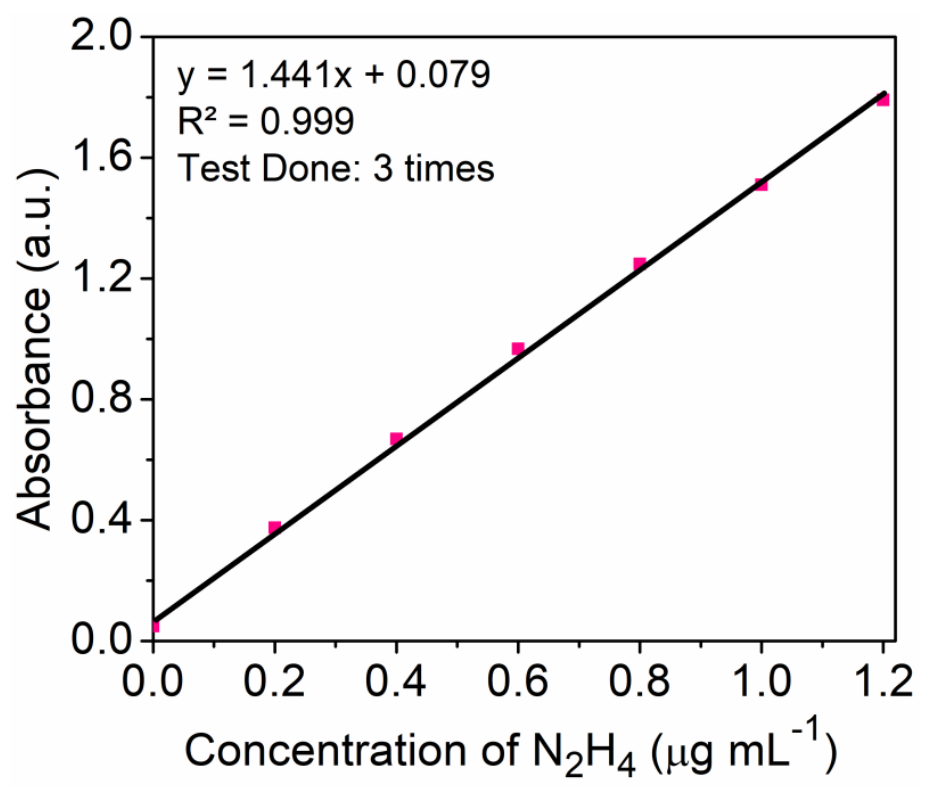

Figure S6: Calibration curve used for determination of $\mathrm{N}_{2} \mathrm{H}_{4}$ concentration.

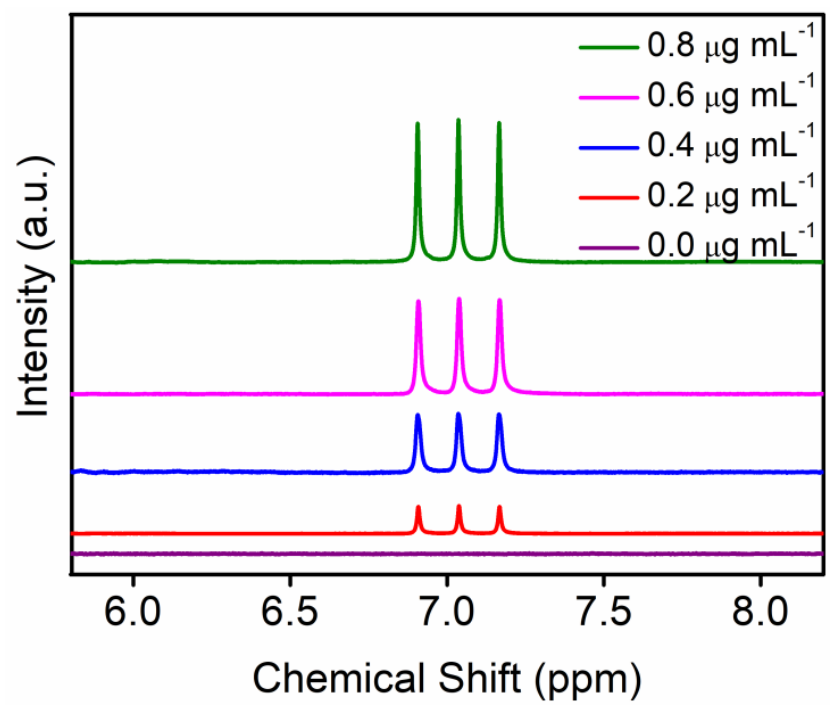

Figure S7: ${ }^{1} \mathrm{H}$ NMR spectra of ${ }^{14}\left(\mathrm{NH}_{4}\right)_{2} \mathrm{SO}_{4}$ with different concentrations 


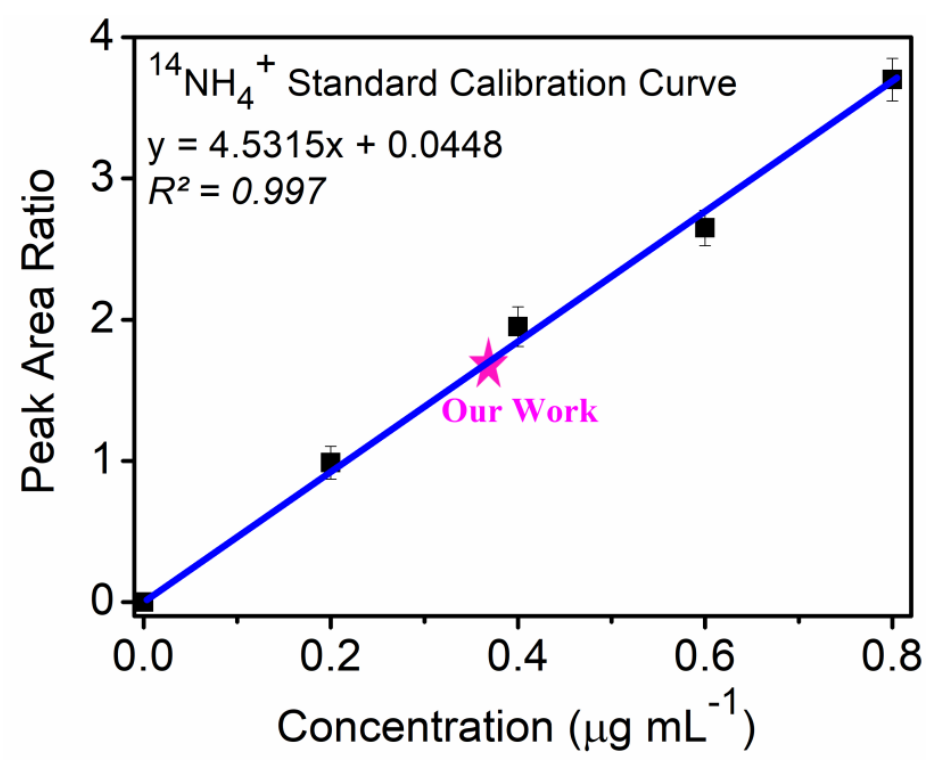

Figure S8: Calibration curve used for the determination of ${ }^{14} \mathrm{NH}_{4}{ }^{+}$concentration

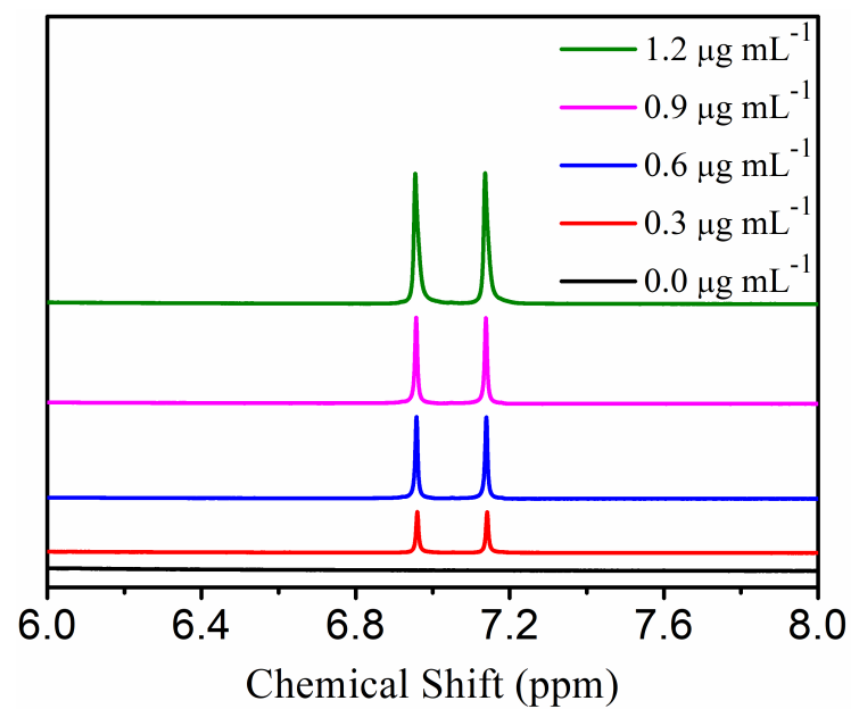

Figure S9: ${ }^{1} \mathrm{H}$ NMR spectra of ${ }^{15} \mathrm{NH}_{4} \mathrm{Cl}$ with different concentrations 


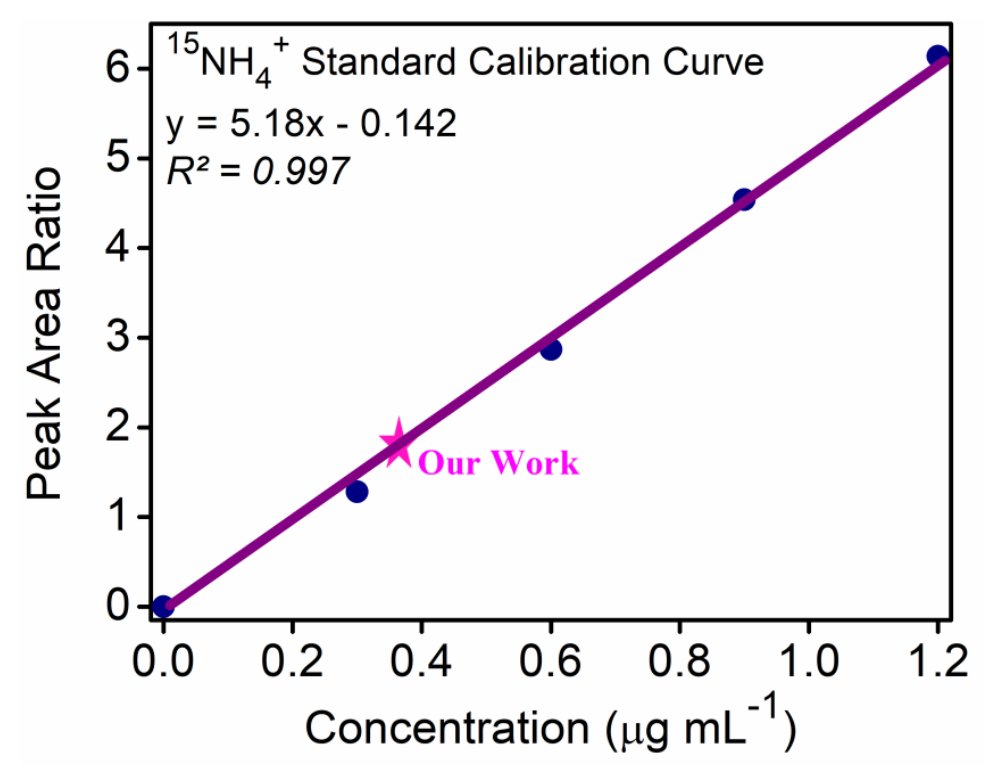

Figure S10: Calibration curve used for the determination of ${ }^{15} \mathrm{NH}_{4}{ }^{+}$concentration

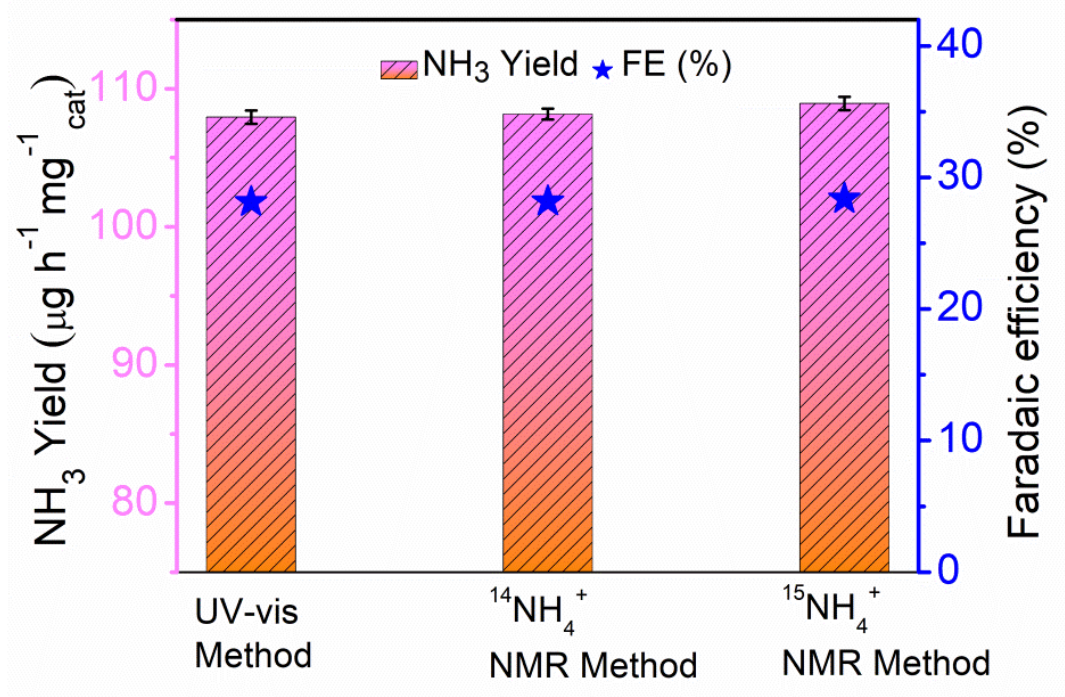

Figure S11: Comparative bar diagram of average $\mathrm{NH}_{3}$ yield rate by $\mathrm{UV}$-visible spectroscopic method, ${ }^{14} \mathrm{NH}_{4}{ }^{+}$NMR method and ${ }^{15} \mathrm{NH}_{4}{ }^{+} \mathrm{NMR}$ method at $-0.3 \mathrm{~V}$ vs RHE. 


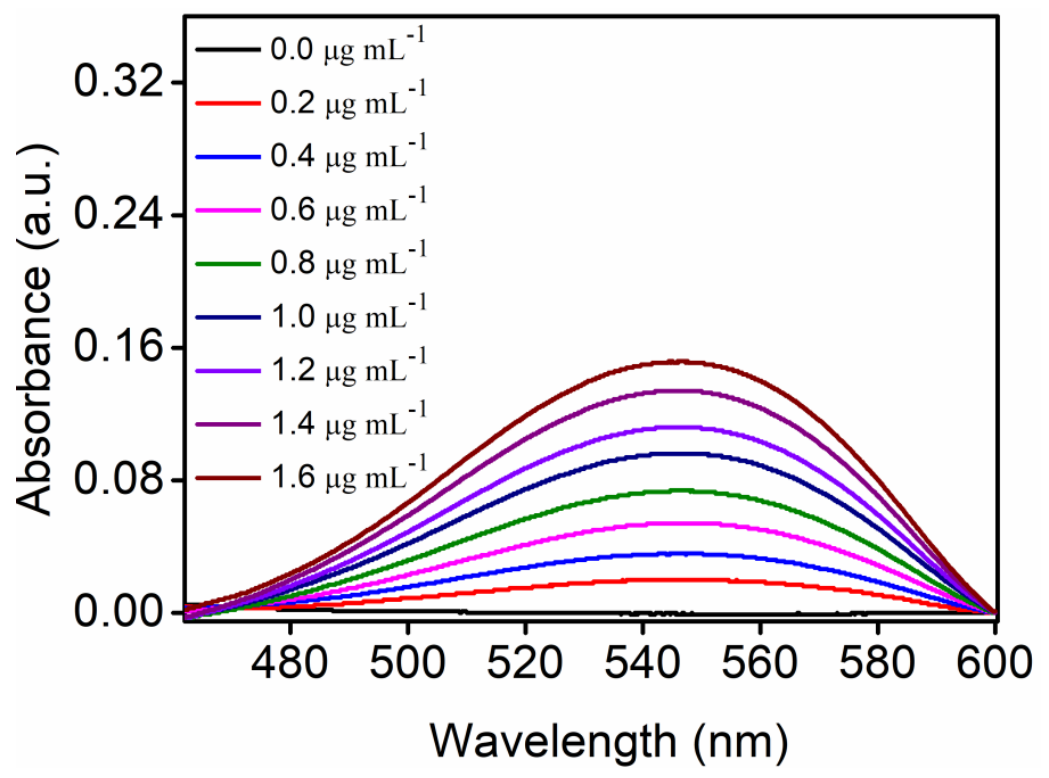

Figure S12: UV-vis absorption spectra of $\mathrm{NO}_{\mathrm{x}}$ of different concentration solution after 900 seconds incubation under ambient condition.

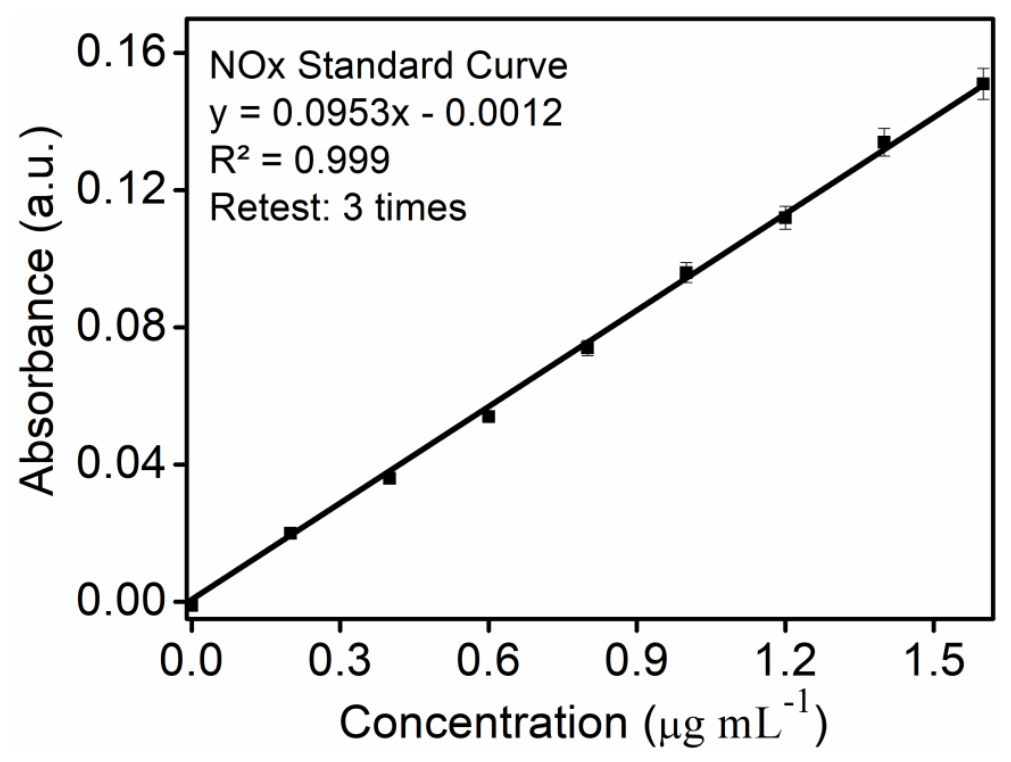

Figure S13: Calibration curve for determination of $\mathrm{NO}_{\mathrm{x}}$ concentration 


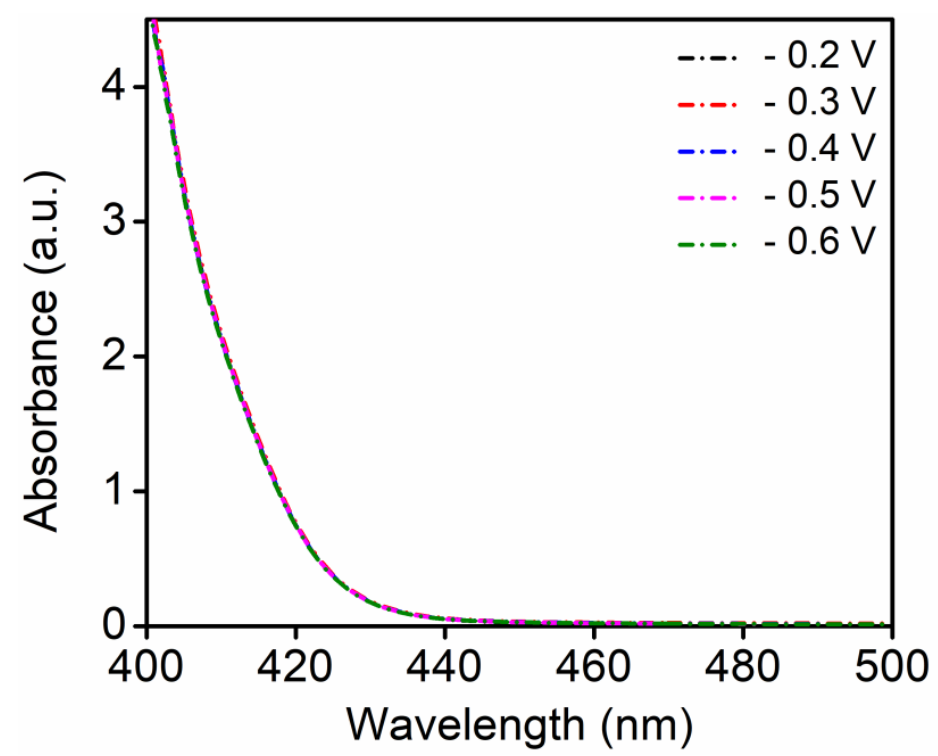

Figure S14: UV-vis absorption spectra of electrolytes at different potentials after 7200 seconds to quantitatively determine $\mathrm{N}_{2} \mathrm{H}_{4}$ concentration.

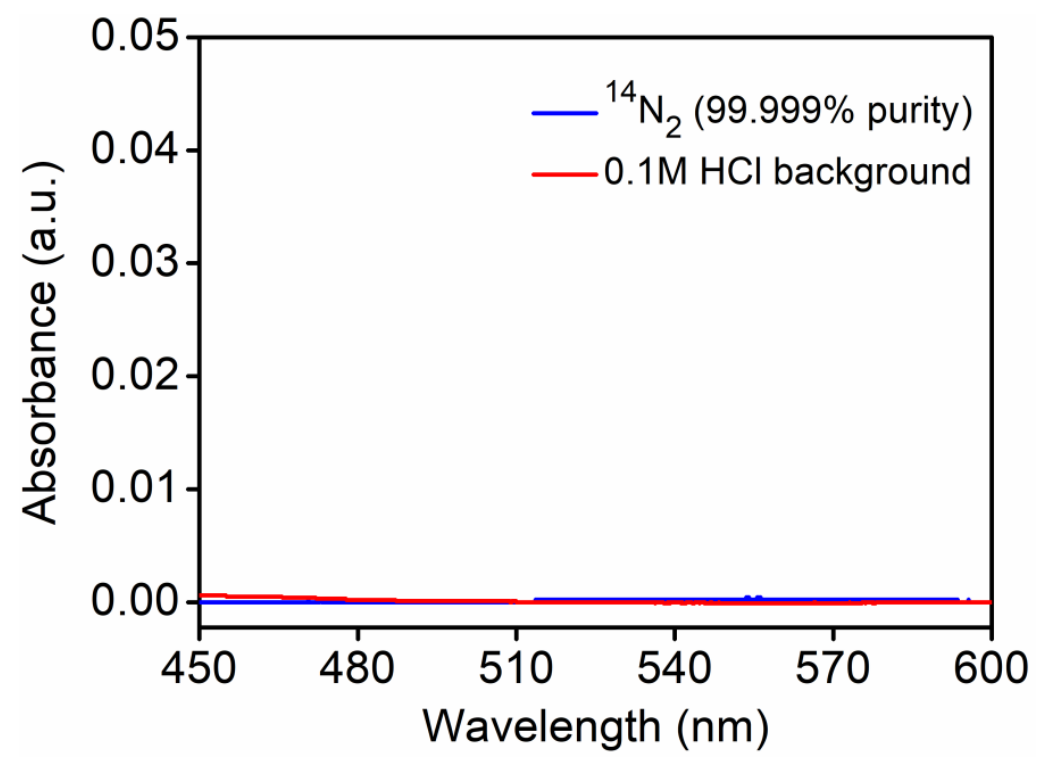

Figure S15: The UV-vis absorption spectra of the $0.1 \mathrm{M} \mathrm{HCl}$ background and the ultra-high purity grade ${ }^{14} \mathrm{~N}_{2}$ (99.999\% purity) purged in $0.1 \mathrm{M} \mathrm{HCl}$ electrolyte; using $N$-(-1-naphthyl)ethylenediamine dihydrochloride spectrophotometric method. The results show that $\mathrm{NO}_{\mathrm{x}}$ does not exist in the ${ }^{14} \mathrm{~N}_{2}$ purged gas. 


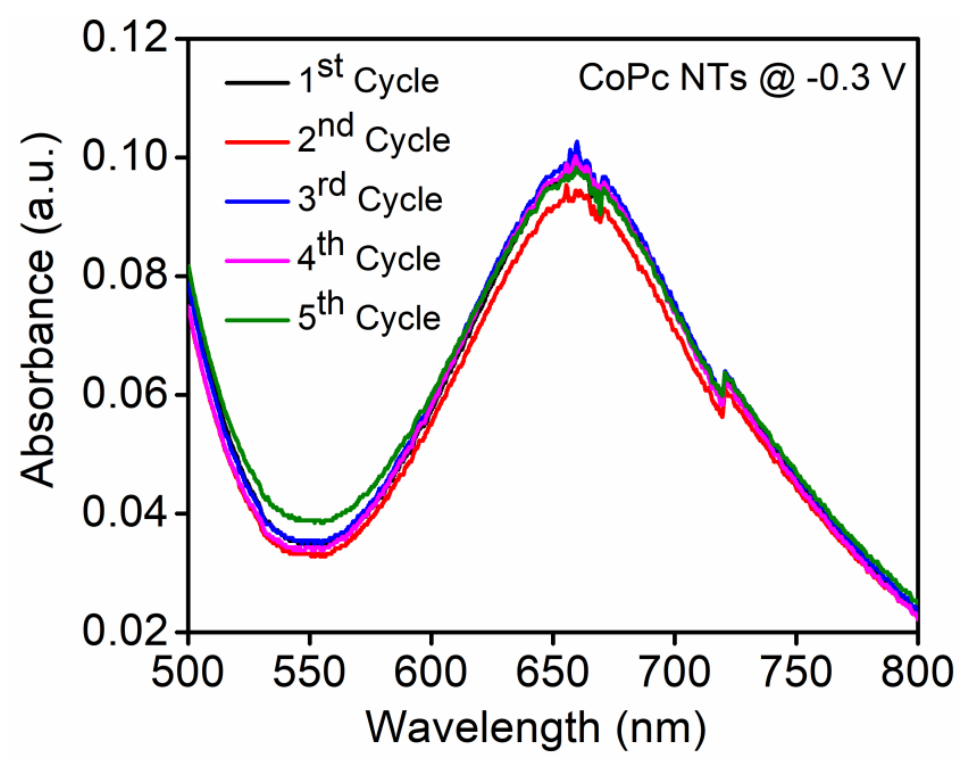

Figure S16: UV-vis absorption spectra of the electrolytes stained with indophenol indicator at 0.3 V vs RHE after 7200 seconds electrolysis at various cycles.

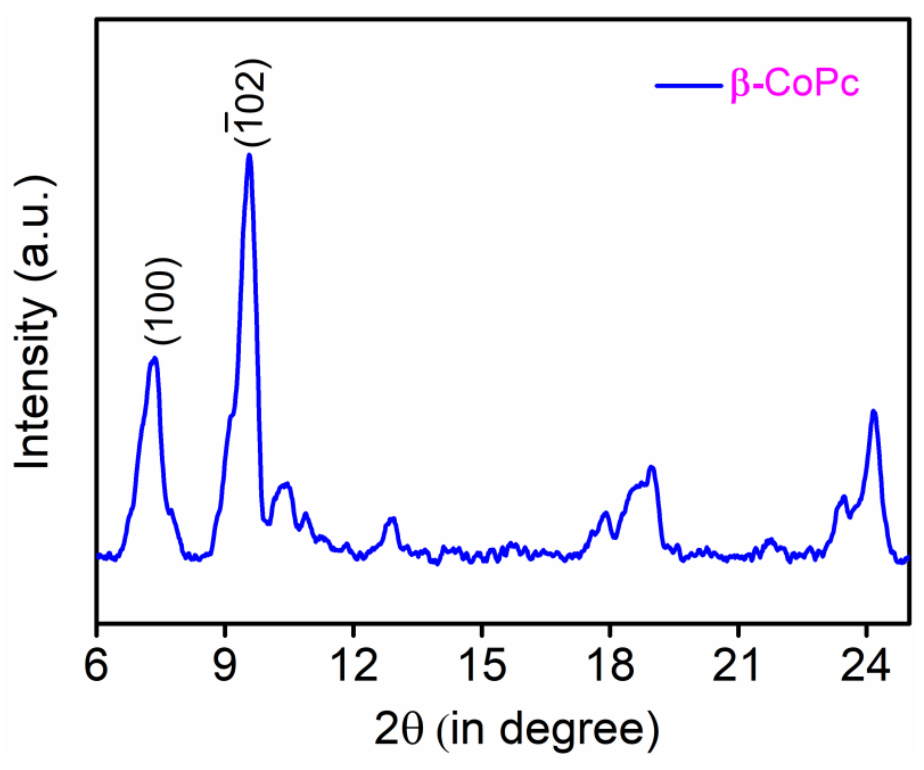

Figure S17: XRD pattern of CoPc NTs after 20 h electrolysis 


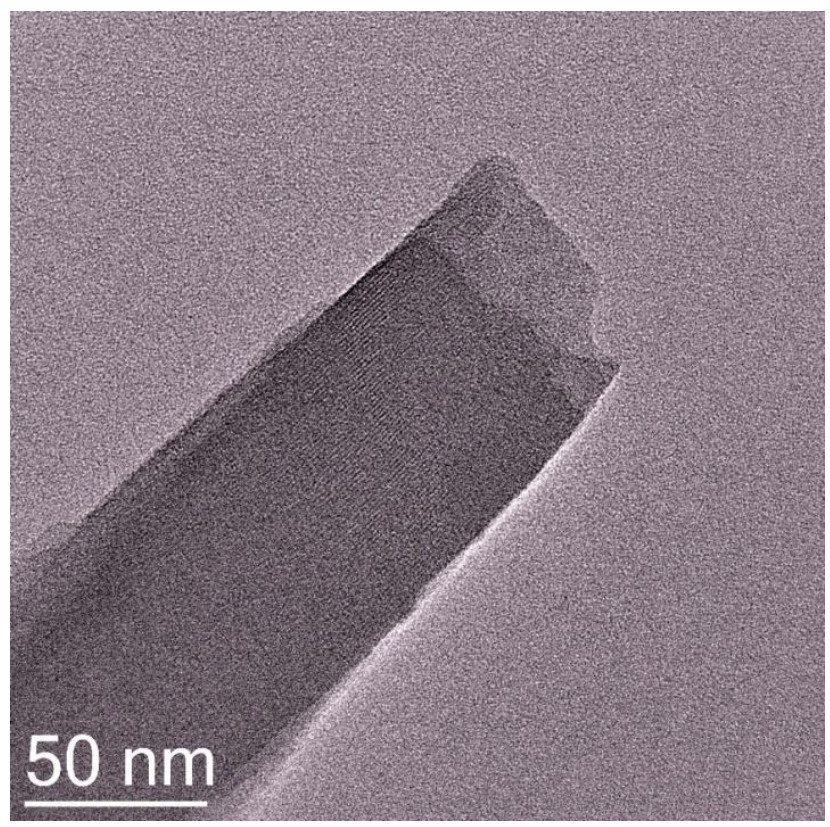

Figure S18: HRTEM image of CoPc nanotube after stability test (20 h duration)

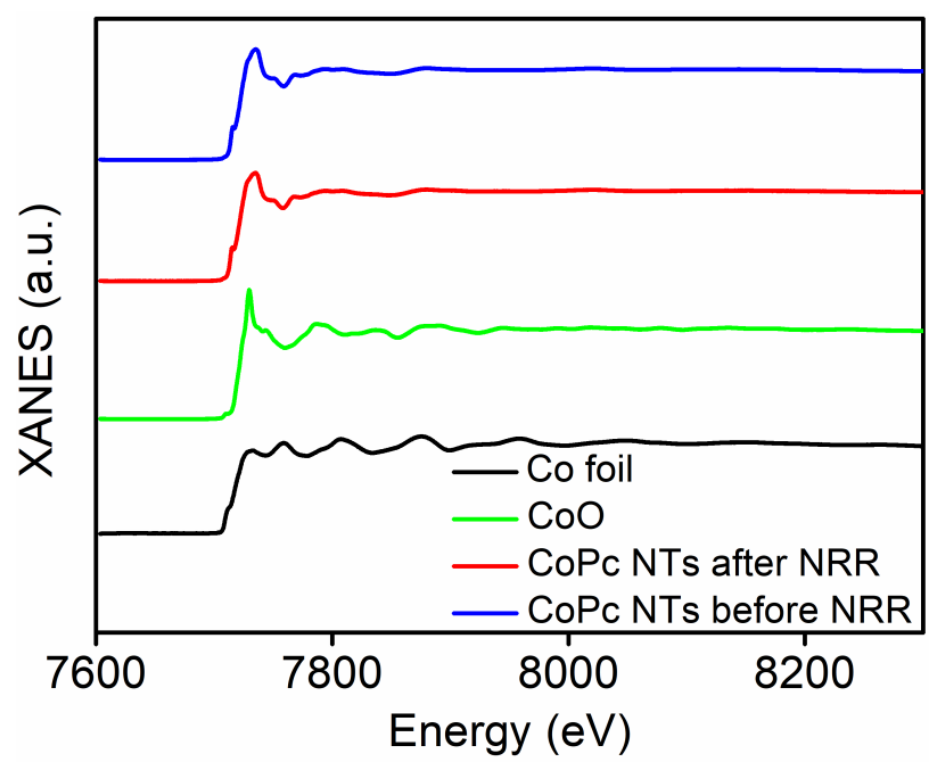

Figure S19: XANES spectra at the Co K-edge of CoPc NTs before and after NRR along with $\mathrm{CoO}$ and $\mathrm{Co}$ foil. 
Table 2: Best fit data of EXAFS fitting of CoPc NTs at Co K-edge.

\begin{tabular}{|c|c|c|c|}
\hline & & $\begin{array}{c}\text { CoPc NTs } \\
\text { Before NRR }\end{array}$ & $\begin{array}{l}\text { CoPc NTs } \\
\text { After NRR }\end{array}$ \\
\hline \multirow[t]{3}{*}{ Co-N } & $\mathrm{CN}(4)$ & $4 \pm 0.1$ & $3.96 \pm 0.1$ \\
\hline & $R(\AA)(1.92)$ & $1.92 \pm 0.1$ & $1.92 \pm 0.1$ \\
\hline & $\sigma^{2}$ & $0.003 \pm 0.001$ & $0.003 \pm 0.001$ \\
\hline \multirow[t]{3}{*}{ Co-C } & CN (8) & $8 \pm 0.2$ & $8 \pm 0.2$ \\
\hline & $R(\AA)(2.94)$ & $2.95 \pm 0.02$ & $2.94 \pm 0.02$ \\
\hline & $\sigma^{2}$ & $0.004 \pm 0.001$ & $0.006 \pm 0.002$ \\
\hline \multirow[t]{3}{*}{ Co-N } & $\mathrm{CN}(3)$ & $3 \pm 0.1$ & $3 \pm 0.1$ \\
\hline & $R(\AA)(3.17)$ & $3.24 \pm 0.02$ & $3.24 \pm 0.02$ \\
\hline & $\sigma^{2}$ & $0.003 \pm 0.001$ & $0.003 \pm 0.001$ \\
\hline
\end{tabular}




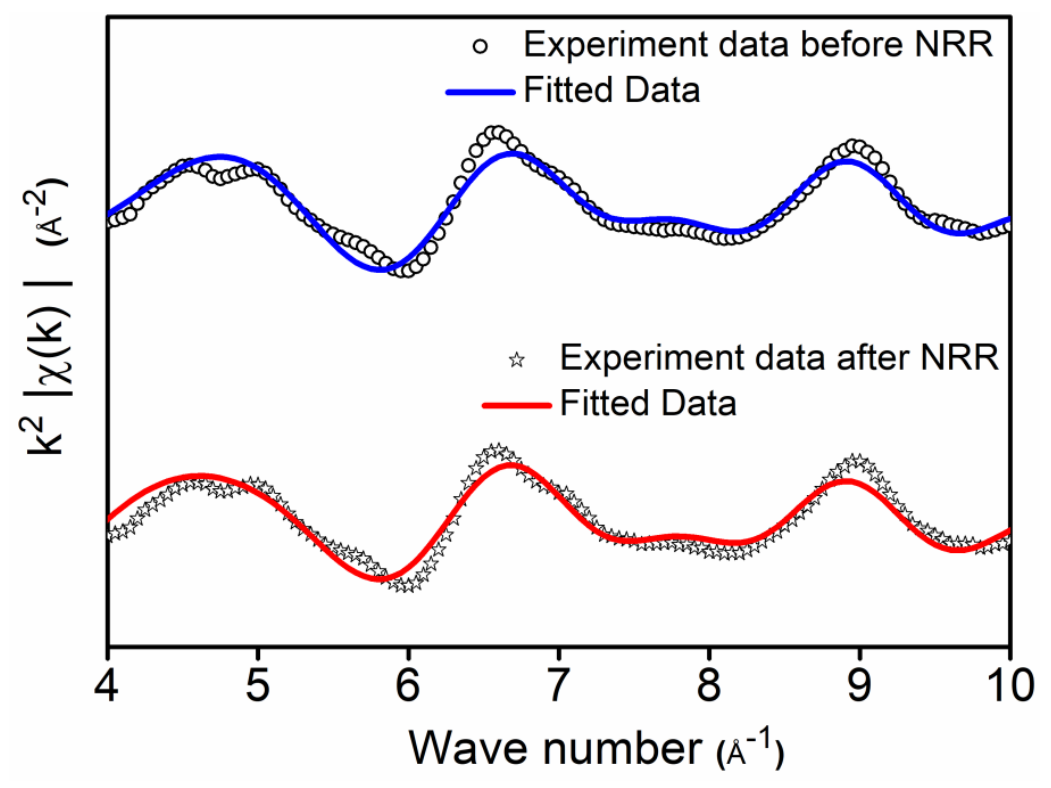

Figure S20: Co K edge EXAFS fitting result for $\mathrm{k}^{2}$ space

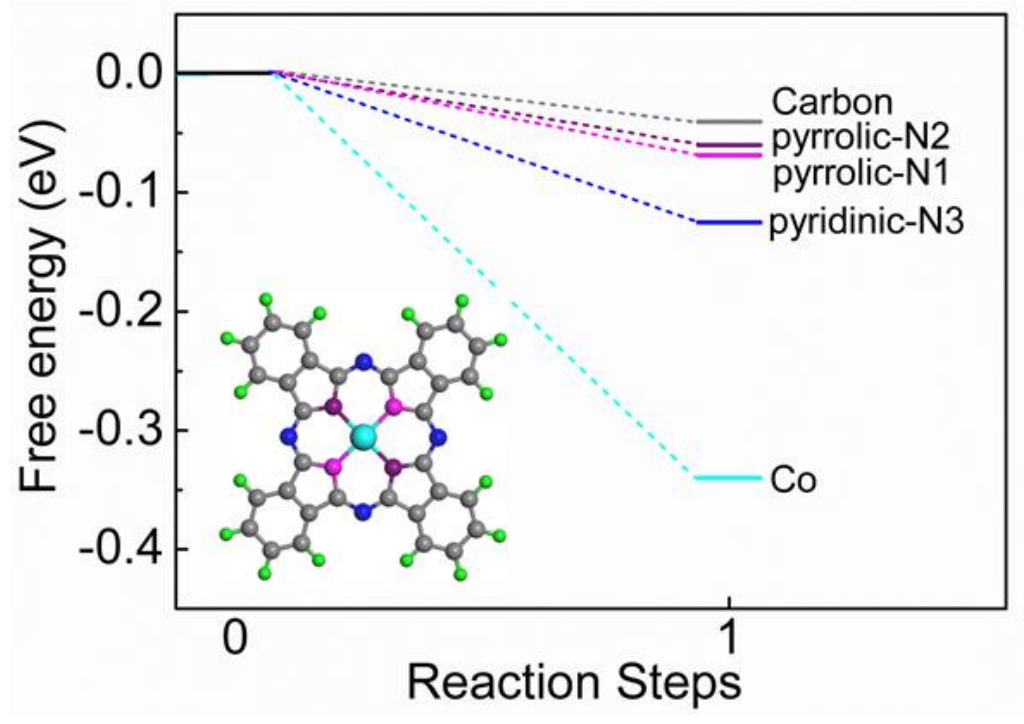

Figure S21: The Free-energy diagrams of $\mathrm{N}_{2}$ adsorption on possible active sites of $\mathrm{CoPc}$ 


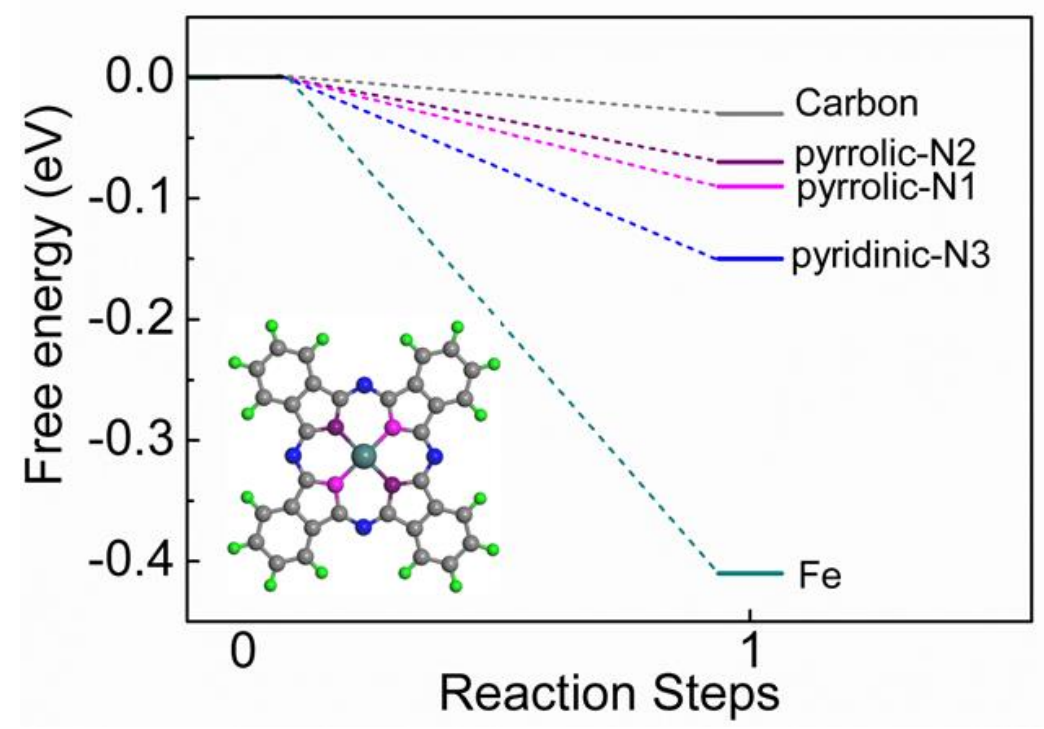

Figure S22: The Free-energy diagrams of $\mathrm{N}_{2}$ adsorption on possible active sites of FePc

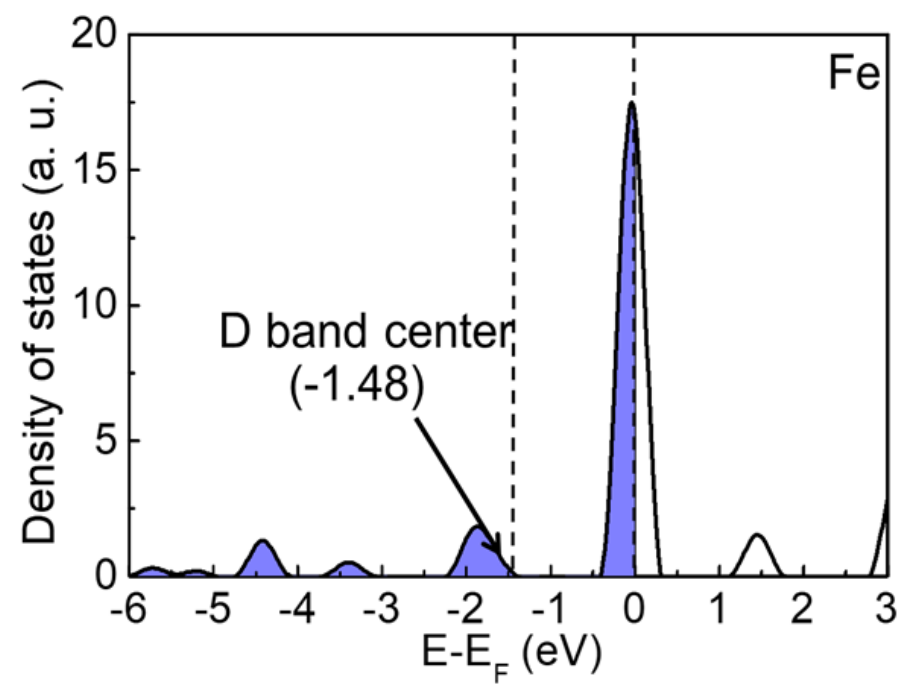

Figure S23: The d orbital partial density of states of Fe center in FePc. The dotted line at zero represents the Fermi energy and the shaded area with blue color shows the occupied energies of d orbital. 
Table 3: Comparison of the NRR activity for CoPc NTs with other transition metal based electro-catalyst in solution media of varying $\mathrm{pH}$ under ambient conditions

\begin{tabular}{|c|c|c|c|c|c|}
\hline Catalyst & Electrolyte & $\begin{array}{l}\text { Potential } \\
\text { (V vs RHE) }\end{array}$ & $\mathrm{NH}_{3}$ yield & FE $(\%)$ & References \\
\hline $\mathrm{MoS}_{2}$ & $0.1 \mathrm{M} \mathrm{Na}_{2} \mathrm{SO}_{4}$ & $-0.5 \mathrm{~V}$ & $8.08 \times 10^{-11} \mathrm{~mol} \mathrm{~s}^{-1} \mathrm{~cm}^{-2}$ & $1.17 \%$ & Adv. Mater. 2018, 30, 1800191 \\
\hline $\mathrm{MoS}_{2}$ nanoflowers & $0.1 \mathrm{M} \mathrm{Na}_{2} \mathrm{SO}_{4}$ & $-0.40 \mathrm{~V}$ & $29.28 \mu \mathrm{g} \mathrm{h}^{-1} \mathrm{mg}^{-1}$ cat & $8.34 \%$ & Adv. Energy Mater. 2018, 8,1801357 \\
\hline $\mathrm{Mo}_{2} \mathrm{C} / \mathrm{C}$ & $0.5 \mathrm{M} \mathrm{Li}_{2} \mathrm{SO}_{4}$ & $-0.3 \mathrm{~V}$ & $11.3 \mu \mathrm{g} \mathrm{h}^{-1} \mathrm{mg}^{-1}$ cat & $7.8 \%$ & Adv. Mater. 2018, 30, 1803694 \\
\hline $\mathrm{a}-\mathrm{Au} / \mathrm{CeO}_{\mathrm{x}}-\mathrm{RGO}$ & $1 \mathrm{M} \mathrm{HCl}$ & $-0.2 \mathrm{~V}$ & $8.3 \mu \mathrm{g} \mathrm{h}^{-1} \mathrm{mg}^{-1}$ cat & $10.1 \%$ & Adv. Mater. 2017, 29, 1700001 \\
\hline Au nanorods & $0.1 \mathrm{M} \mathrm{KOH}$ & $-0.2 \mathrm{~V}$ & $1.648 \mu \mathrm{g} \mathrm{h}^{-1} \mathrm{~cm}^{-2}$ & $4.02 \%$ & Adv. Mater. 2017, 29, 1604799 \\
\hline $\mathrm{Pd}_{0.2} \mathrm{Cu}_{0.8} / \mathrm{RGO}$ & $0.1 \mathrm{M} \mathrm{KOH}$ & $-0.2 \mathrm{~V}$ & $2.80 \mu \mathrm{g} \mathrm{h}^{-1} \mathrm{mg}^{-1}$ cat & $\sim 4.3 \%$ & Adv. Energy Mater. 2018, 8,1800124 \\
\hline $\mathrm{Au}-\mathrm{TiO}_{2}$ & $1 \mathrm{M} \mathrm{HCl}$ & $-0.2 \mathrm{~V}$ & $21.4 \mu \mathrm{g} \mathrm{h}^{-1} \mathrm{mg}^{-1}$ cat & $8.11 \%$ & Adv. Mater. 2017, 29, 1606550 \\
\hline $\mathrm{W}_{2} \mathrm{~N}_{3}$ nanosheet & $0.10 \mathrm{M} \mathrm{KOH}$ & $-0.2 \mathrm{~V}$ & $\begin{array}{l}11.66 \pm 0.98 \mu \mathrm{g} \mathrm{h}^{-1} \\
\mathrm{mg}_{\text {cat }}^{-1}\end{array}$ & $\begin{array}{l}11.67 \pm \\
0.93 \%\end{array}$ & Adv. Mater. 2019, 31, 1902709 \\
\hline $\mathrm{NiO} / \mathrm{G}$ & $0.1 \mathrm{M} \mathrm{Na}_{2} \mathrm{SO}_{4}$ & $-0.7 \mathrm{~V}$ & $18.6 \mu \mathrm{g} \mathrm{h}^{-1} \mathrm{mg}^{-1}$ cat & $7.8 \%$ & $\begin{array}{l}\text { ACS Appl. Energy Mater. 2019, } 2 \text {, } \\
2288-2295\end{array}$ \\
\hline $\mathrm{Nb}_{2} \mathrm{O}_{5}$ nanofiber & $0.1 \mathrm{M} \mathrm{HCl}$ & $-0.55 \mathrm{~V}$ & $43.6 \mu \mathrm{g} \mathrm{h}^{-1} \mathrm{mg}^{-1}$ cat & $9.26 \%$ & Nano Energy, 2018, 52, 264-270 \\
\hline $\begin{array}{c}\text { Mo doped } \mathrm{MnO}_{2} \\
\text { nanoflowers }\end{array}$ & $0.1 \mathrm{M} \mathrm{Na}_{2} \mathrm{SO}_{4}$ & $-0.5 \mathrm{~V}$ & $36.6 \mu \mathrm{g} \mathrm{h}^{-1} \mathrm{mg}^{-1}$ cat & $7.9 \%$ & Appl. Catal. B, 2020, 264, 118525 \\
\hline $\begin{array}{c}\mathrm{Cr}_{2} \mathrm{O}_{3} \\
\text { microspheres }\end{array}$ & $0.1 \mathrm{M} \mathrm{Na}_{2} \mathrm{SO}_{4}$ & $-0.9 \mathrm{~V}$ & $25.3 \mu \mathrm{g} \mathrm{h}^{-1} \mathrm{mg}^{-1}$ cat & $6.78 \%$ & ACS Catal. 2018, 8, 9, 8540-8544 \\
\hline $\mathrm{FePc} / \mathrm{C}$ & $0.1 \mathrm{M} \mathrm{Na}_{2} \mathrm{SO}_{4}$ & $-0.3 \mathrm{~V}$ & $10.25 \mu \mathrm{g} \mathrm{h}^{-1} \mathrm{mg}^{-1}$ cat & $10.50 \%$ & ACS Catal. 2019, 9, 7311-7317 \\
\hline $\mathrm{Fe}-\mathrm{CeO}_{2}$ & $0.5 \mathrm{M} \mathrm{LiClO}_{4}$ & $-0.5 \mathrm{~V}$ & $26.2 \mu \mathrm{g} \mathrm{h}^{-1} \mathrm{mg}^{-1}$ cat & $5.5 \%$ & $\begin{array}{l}\text { J. Mater. Chem. A, 2020, 8, 5865- } \\
5873\end{array}$ \\
\hline CoO-QD/RGO & $0.1 \mathrm{M} \mathrm{Na}_{2} \mathrm{SO}_{4}$ & $-0.6 \mathrm{~V}$ & $21.5 \mu \mathrm{g} \mathrm{h}^{-1} \mathrm{mg}^{-1}$ cat & $8.3 \%$ & $\begin{array}{l}\text { J. Mater. Chem. A, 2019, 7, 4389- } \\
4394\end{array}$ \\
\hline
\end{tabular}




\begin{tabular}{|c|c|c|c|c|c|}
\hline $\mathrm{TiO}_{2}-\mathrm{RGO}$ & $0.1 \mathrm{M} \mathrm{Na}_{2} \mathrm{SO}_{4}$ & $-0.90 \mathrm{~V}$ & $15.13 \mu \mathrm{g} \mathrm{h}^{-1} \mathrm{mg}^{-1}$ cat & $3.3 \%$ & $\begin{array}{l}\text { J. Mater. Chem. A, 2018, 6, 17303- } \\
17306\end{array}$ \\
\hline FePc/O-MWCNT & $0.1 \mathrm{M} \mathrm{HCl}$ & $-0.3 \mathrm{~V}$ & $36 \mu \mathrm{g} \mathrm{h}^{-1} \mathrm{mg}^{-1}$ cat & $9.73 \%$ & Chem. Commun. 2019, 55, 14111 \\
\hline $\mathrm{Mn}_{3} \mathrm{O}_{4}$ nanocubes & $0.1 \mathrm{M} \mathrm{Na}_{2} \mathrm{SO}_{4}$ & $-0.8 \mathrm{~V}$ & $11.6 \mu \mathrm{g} \mathrm{h}^{-1} \mathrm{mg}^{-1}$ cat & $3.0 \%$ & Small, 2018, 14, 1803111 \\
\hline $\begin{array}{c}\text { Spinel } \mathrm{LiMn}_{2} \mathrm{O}_{4} \\
\text { nanofiber }\end{array}$ & $0.1 \mathrm{M} \mathrm{HCl}$ & $-0.50 \mathrm{~V}$ & $15.83 \mu \mathrm{g} \mathrm{h}^{-1} \mathrm{mg}^{-1}$ cat & $7.44 \%$ & Inorg. Chem. 2019, 58, 9597-9601 \\
\hline $\mathrm{Zr}^{4+}$-doped $\mathrm{TiO}_{2}$ & $0.1 \mathrm{M} \mathrm{KOH}$ & $-0.45 \mathrm{~V}$ & $8.90 \mu \mathrm{g} \mathrm{h}^{-1} \mathrm{~cm}^{-2}$ & $17.3 \%$ & Nat. Commun. 2019, 10, 2877 \\
\hline NCM-Au NPs & $0.1 \mathrm{M} \mathrm{HCl}$ & $\begin{array}{l}-0.2 \mathrm{~V} \text { (yield) } \\
-0.1 \mathrm{~V}(\mathrm{FE})\end{array}$ & $0.36 \mathrm{~g} \mathrm{~m}^{-2} \mathrm{~h}^{-1}$ & $22 \%$ & $\begin{array}{l}\text { Angew. Chem. Int. Ed. 2018, 57, } \\
12360-12364\end{array}$ \\
\hline CoPc NTs & 0.1 M HCl & $-0.3 \mathrm{~V}$ & $107.9 \mu \mathrm{g} \mathrm{h}^{-1} \mathrm{mg}^{-1}$ cat & $27.7 \%$ & This Work \\
\hline
\end{tabular}




\section{SI 22: References}

(1) Watt, G. W.; Chrisp, J. D. A Spectrophotometric Method for Determination of Hydrazine. Anal. Chem. 1952, 24, 2006-2008.

(2) Wang, M.; Liu, S.; Ji, H.; Liu, J.; Yan, C.; Qian, T. Unveiling the Essential Nature of Lewis Basicity in Thermodynamically and Dynamically Promoted Nitrogen Fixation. Adv. Funct. Mater. 2020, 30 (32), 1-7.

(3) Kresse, G.; Joubert, D. From Ultrasoft Pseudopotentials to the Projector Augmented-Wave Method. Phys. Rev. B 1999, 59, 1758-1775.

(4) Perdew, John P.; Burke, Kieron; Ernzerhof, Matthias. Generalized Gradient Approximation Made Simple. Phys. Rev. Lett. 1996, 77, 3865.

(5) Sinthika, S.; Waghmare, Umesh V.; Thapa, Ranjit. Structural and Electronic Descriptors of Catalytic Activity of Graphene-Based Materials: First-Principles Theoretical Analysis. Small 2017, 14, 1703609.

(6) Poswal, A. K.; Agrawal, A.; Yadav, A. K.; Nayak, C.; Basu, S.; Kane, S. R.; Garg, C. K.; Bhattachryya, D.; Jha, S. N.; Sahoo, N. K. Commissioning and First Results of Scanning Type EXAFS Beamline (BL-09) at INDUS-2 Synchrotron Source. AIP Conf. Proc. 2014, 1591, 649651.

(7) Basu, S.; Nayak, C.; Yadav, A. K.; Agrawal, A.; Poswal, A. K.; Bhattacharyya, D.; Jha, S.

N.; Sahoo, N. K. A Comprehensive Facility for EXAFS Measurements at the INDUS-2 Synchrotron Source at RRCAT, Indore, India. J. Phys. Conf. Ser. 2014, 493 (1), 3-7.

(8) X-Ray Absorption: Principles, Applications, Techniques of EXAFS, SEXAFS and XANES; 
edited by D. C. Konigsberger and R. Prince.; Wiley, New York, 1988.

(9) Newville, M.; Ravel, B.; Haskel, D.; Rehr, J. J.; Stern, E. A.; Yacoby, Y. Analysis of Multiple-Scattering XAFS Data Using Theoretical Standards. Phys. B Phys. Condens. Matter 1995, 208-209, 154-156.

(10) Ji, X.; Zou, T.; Gong, H.; Wu, Q.; Qiao, Z.; Wu, W.; Wang, H. Cobalt Phthalocyanine Nanowires: Growth, Crystal Structure, and Optical Properties. Cryst. Res. Technol. 2016, 51 (2), $154-159$.

(11) Kumar, A.; Samanta, S.; Latha, S.; Debnath, A. K.; Singh, A.; Muthe, K. P.; Barshilia, H. C. Enhanced $\mathrm{Cl}_{2}$ Sensitivity of Cobalt-Phthalocyanine Film by Utilizing a Porous Nanostructured Surface Fabricated on Glass. RSC Adv. 2017, 7 (7), 4135-4143. 